\title{
The Accuracy of Holes Drilled in the Side Surface of Plywood
}

\author{
Maciej Sydor, ${ }^{\mathrm{a}, \mathrm{b}, *}$ Tomasz Rogoziński, ${ }^{a}$ Kinga Stuper-Szablewska, ${ }^{\mathrm{a}}$ and \\ Karol Starczewski ${ }^{\mathrm{b}}$
}

\begin{abstract}
Dimensional accuracy of machining translates into susceptibility to defects in assembly of furniture elements. In the initial drilling phase, the tip of the drill may slip due to the properties of the workpiece, which may result in inaccurate machining. Taking this into account, it was decided to investigate this phenomenon for drilling in the side of the plywood board. Samples for testing were made of $18 \mathrm{~mm}$ thick, 13 layer birch-alder plywood, covered with melamine film, glued with phenol-formaldehyde glue. With the use of an industrial dowel drilling machine, 30 holes in each of three examined layer were made. All holes were made parallel to the layers - on the side of the plywood board, and their axes were located in three adjacent layers: the birch veneer layer, the adhesive layer, and the alder veneer layer. Two types of geometric accuracy of holes were analyzed: the distance between the real center of the hole and the nominal position and also the inclination of the hole axis from the nominal axis. The holes made in the adhesive layer showed approximately twice larger deviations compared with the holes made in two adjacent layers of veneer. There was no significant relationship between the deviations of the angle of holes axis and the inaccuracies in the position of their centers. Main conclusion: When drilling in the side surface of the plywood board, less accurate holes are obtained if the hole axis is located in the adhesive layer, and there is more accuracy if the hole axis is located in the veneer layer.
\end{abstract}

Keywords: Plywood; Drilling; Wandering of drill

Contact information: a: Faculty of Wood Technology, Poznań University of Life Sciences, ul. Wojska Polskiego 28, 60-637 Poznań, Poland; b: Digitouch sp. z o.o., ul. Różana 6, 62-002 Suchy Las, Poland;

*Corresponding author: maciej.sydor@up.poznan.pl

\section{INTRODUCTION}

Holes in wood and wood-based materials are usually made to attach fasteners $(e . g$. with screws furniture dowels and other connectors (Smardzewski 2015; Sydor 2019; Sydor and Wieloch 2009). In case of industrial furniture production, holes are made with multispindle drill. Among many other furniture materials, plywood, a multilayer composite made of wood veneers glued in layers, are used. The adhesive joint between the individual veneer layers affects the machinability of the plywood (Guo et al. 2018). As a result, when making deep holes (parallel to the of veneer layers) in the side of a board, there are usually problems with their geometrical accuracy. This applies in particular to drilling deep holes of small diameter, where an unfavourable wandering of drill may occur. This phenomenon may result in an inadequate hole position or one that is not parallel to its axis (tilted axis of hole). Ultimately, this may result in the improper assembly of furniture components. An example of furniture particularly sensitive to inaccuracies of preparation are modular polymorphic furniture (Starczewski 2016; Laskowska and Sydor 2018). The pin connector 
used in them requires small-diameter holes (typically diameter 3 to $4 \mathrm{~mm}$ ) of relatively large depth (60 to $100 \mathrm{~mm})$. These holes are usually made both perpendicular and parallel to the layers of veneers (in a face and in a side of plywood sheets; Fig. 1). The most commonly used board thickness range for cabinet furniture is from 16 to $20 \mathrm{~mm}$.

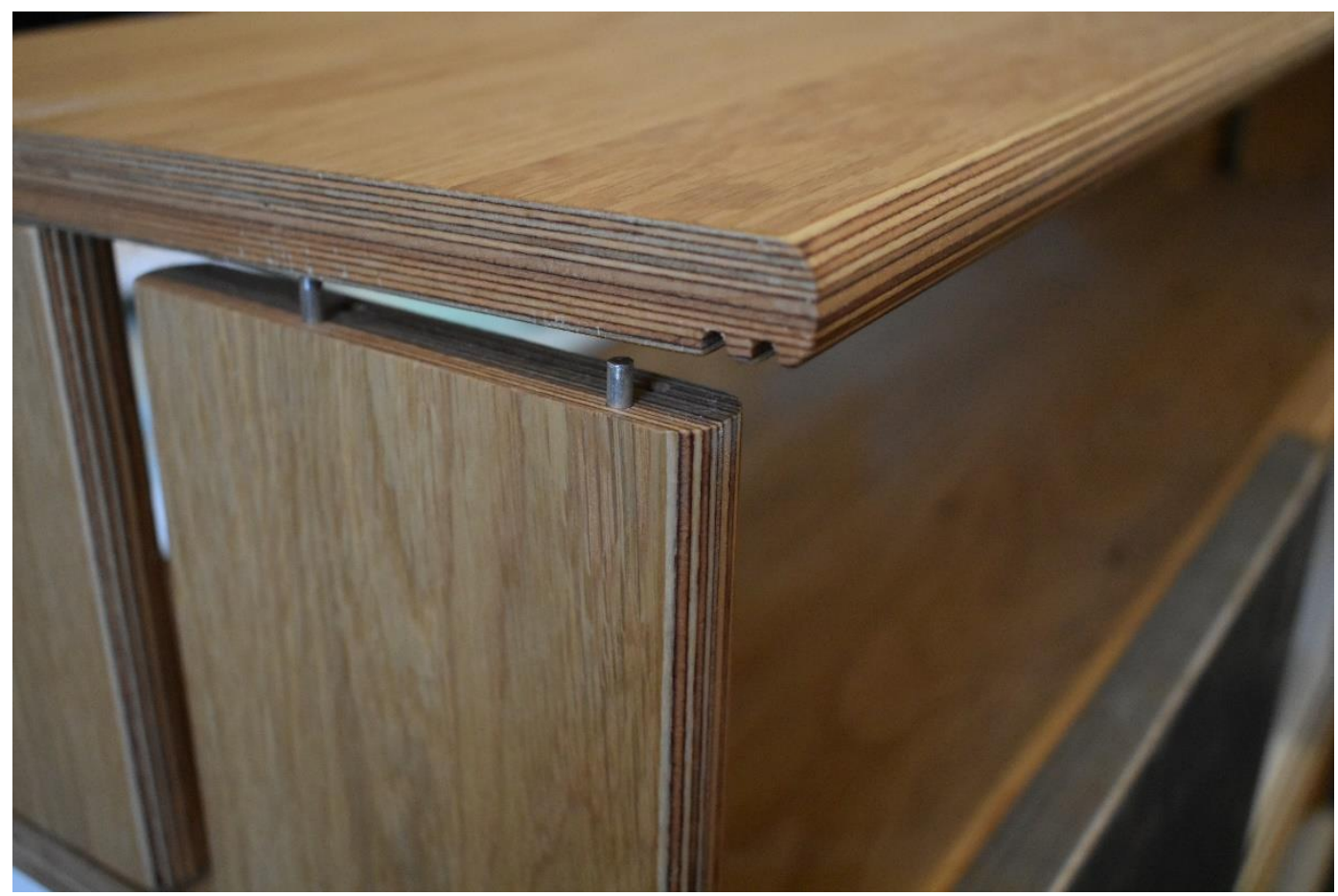

Fig. 1. Furniture with pin connectors requiring long holes in plywood (photo by M.S.)

The technological drilling process involves four phases (Gong et al. 2005). The first phase lasts until the rotating drill starts touching the workpiece. The second phase begins when the tip of the drill is in contact with the workpiece. This phase involves a socalled drill slip, a random phenomenon that proceeds in a manner resultant from the properties of both material and the drill. The slip only occurs during several drill turns, after which the end of the drill stabilizes in a new position, sometimes deviated from the nominal position, and begins penetrate the workpiece. The third phase, penetration of the drill tip, begins after the slip has stopped and the drill forms the full diameter of the drilled hole. The fourth phase begins when the entire drill bit penetrates the workpiece and the side surface of the drill comes to contact with the opening wall. This phase ends when the drill reaches the full depth of the hole. The second phase phenomena are responsible for the deviation of the hole centre from the nominal position, while the phenomena occurring in the third phase mainly correspond to the deviation of the resultant axis as compared with the nominal one (Gong et al. 2005).

The accuracy of the dimensions of the pilot holes for furniture fasteners has a large impact on the susceptibility to assembly and on the strength performance of furniture joints (Branowski et al. 2018). Due to the layered structure of the plywood, the drilling process takes place in a specific way, different in case of other wood composites.

The available scientific literature on drilling conditions in plywood is given in Table 1. 
Table 1. Literature on Drilling Operations Typically Employed for Plywood

\begin{tabular}{|c|c|c|}
\hline References & Remarks & Main conclusions \\
\hline $\begin{array}{c}\text { (Podziewski \& } \\
\text { Górski 2012) }\end{array}$ & $\begin{array}{c}\text { Drilling perpendicular to layers. } \\
\text { Spindle speed } 6000 \mathrm{rpm} \text {. Seven feeds } \\
\text { per revolution: } 0.1,0.15,0.20,0.25 \text {, } \\
0.3,0.5,0.7 \mathrm{~mm} .\end{array}$ & $\begin{array}{c}\text { Strong rectilinear effect of feed rate } \\
\text { on the axial force }(\mathrm{N}) \text { and on the } \\
\text { cutting torque }(\mathrm{Nm}) .\end{array}$ \\
\hline $\begin{array}{c}\text { (Goodell \& } \\
\text { Phillips 1944) }\end{array}$ & $\begin{array}{l}\text { Drilling perpendicular to layers. } \\
\text { Spindle speed } 200 \text { to } 4,000 \text { rpm. } \\
\text { Feed } 1 / 2 \text { inch to } 100 \text { inches per } \\
\text { minute. }\end{array}$ & $\begin{array}{l}\text { Slow feed increased the screw } \\
\text { withdrawal force from the holes made } \\
\text { in plywood. }\end{array}$ \\
\hline $\begin{array}{c}\text { (Podziewski \& } \\
\text { Górski 2011) }\end{array}$ & $\begin{array}{c}\text { Drilling perpendicular to layers. } \\
\text { Spindle speeds: } 3000 \text { rpm, } 6000 \mathrm{rpm} \\
\text { and } 9000 \mathrm{rpm} \text {. Five feeds per } \\
\text { revolution: } 0.10,0.15,0.20,0.25,0.30 \\
\mathrm{~mm} .\end{array}$ & $\begin{array}{l}\text { The effect of spindle speed on drill } \\
\text { advance force was negligible. In case } \\
\text { of plywood, the relationship between } \\
\text { feed per revolution and feeding force } \\
\text { were proportional. }\end{array}$ \\
\hline $\begin{array}{c}\text { (Podziewski et } \\
\text { al. 2018) }\end{array}$ & $\begin{array}{c}\text { Drilling perpendicular to layers. } \\
\text { Spindle speed } 6000 \mathrm{rpm} \text {. Seven feeds } \\
\text { per revolution: } 0.1,0.15,0.20,0.25 \\
0.30,0.50,0.70 \mathrm{~mm} .\end{array}$ & $\begin{array}{l}\text { Plywood susceptibility to drilling was } \\
\text { similar to the susceptibility of OSB } \\
\text { board. It makes a serious challenge in } \\
\text { respect of processing quality. }\end{array}$ \\
\hline $\begin{array}{c}\text { (Rogoziński et } \\
\text { al. 2015) }\end{array}$ & $\begin{array}{l}\text { Drilling perpendicular to layers. } \\
\text { Spindle speed } 6000 \mathrm{rpm} \text {. Feed per } \\
\text { revolution } 0.15 \mathrm{~mm} \text {. }\end{array}$ & $\begin{array}{l}\text { Drilling in plywood produced a smaller } \\
\text { amount of fine dust than drilling in } \\
\text { hardboard }\end{array}$ \\
\hline
\end{tabular}

The authors of the publications presented in Table 5 focused on the research of drilling processes in face of plywood boards (perpendicular to the veneer layers). The analysed literature on drilling in plywood boards showed no description of the experiment of drilling in side board surfaces (parallel to veneer layers).

Due to the internal structure of the plywood, the location of the hole in relation to the individual layers of plywood may prove important. Therefore, in order to determine the impact of the hole axis on the non-homogeneous side surface of the hardwood plywood, the drilling experiment was prepared, where holes were drilled in the side surface of such a board and the deviations of their resultant position (distance hole centres from the line being the nominal dimension) and angle deviation of holes (tilt of hole axis) were measured.

\section{EXPERIMENTAL}

\section{Material}

Three samples for testing were made of 13 layer hardwood (birch and alder) plywood covered with melamine film glued with water resistant glue, based on phenolformaldehyde resin. They were $320 \mathrm{~mm}$ in length, $45 \mathrm{~mm}$ width, and $18 \mathrm{~mm}$ thick. This enabled the formation of 30 holes in each of them. The most important physical parameters of the plywood used in the experiment are summarized in Table 2.

Table 2. Important Physical Parameters of the Plywood Samples

\begin{tabular}{|c|c|l|l|c|}
\hline Parameter & \multicolumn{1}{|c|}{$\begin{array}{c}\text { Density (kg } \\
\mathbf{m - 3})\end{array}$} & MOE (MPa) & \multicolumn{1}{|c|}{ MOR (MPa) } & $\begin{array}{c}\text { Hardness } \\
\text { (HB) }\end{array}$ \\
\hline Value & $660.1(15.3)$ & $7601(67.0)$ & $70.1(4.2)$ & $2.8(0.3)$ \\
\hline \multicolumn{2}{|c|}{ The standard deviations in parentheses were from 10 replicate data of the sample. } \\
\hline
\end{tabular}


Samples for testing were cut from one piece of the plate to obtain possibly homogeneous material properties for each of the three samples. This was because the properties of plywood, even made of the same species of wood and using the same adhesive, may differ from each other. These differences result from the heterogeneity of the raw material (veneer) and from the possible technological differences in the production of plywood (e.g. temperature, pressure or pressing time) or from various storage conditions. The holes made under the experiment were intended for mounting steel spigots in the form of $57 \mathrm{~mm}$ pins of $3.4 \mathrm{~mm}$ nominal diameter.

\section{Methods}

To make holes in the side surface of the plywood board, a multi-spindle dowel drilling machine was used (Felder FD 21 professional, Fig. 2). The machine had 21 spindles (11 with right-hand rotation and 10 with left-hand rotation). A central right-turn spindle was used to drill all holes. The spacing between the holes was $10 \mathrm{~mm}$.

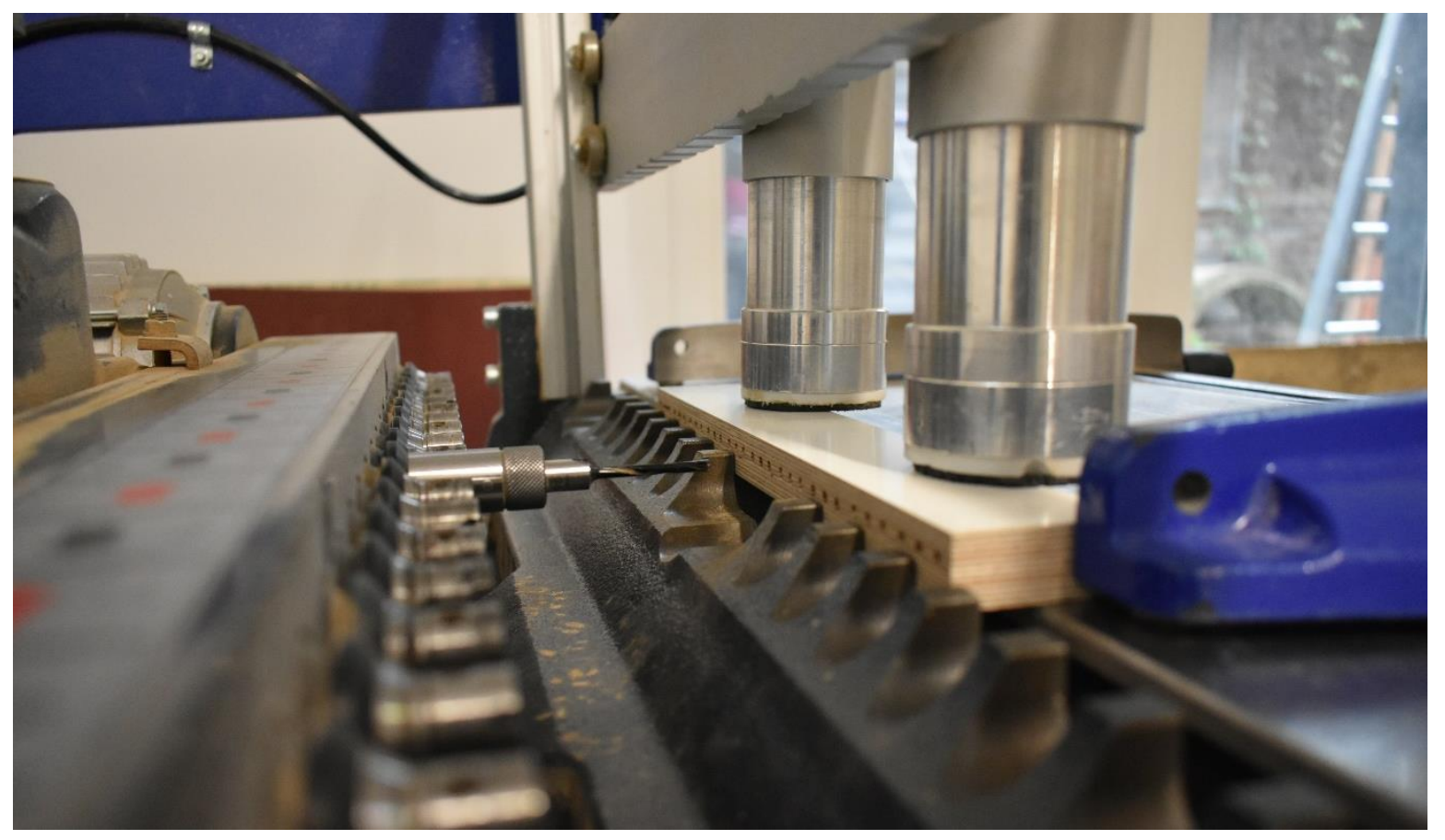

Fig. 2. The method of making holes (photo by M.S.)

The twist drill bit was used (with cylindrical right-handed shank of $3.8 \mathrm{~mm}$ nominal diameter, with $75 \mathrm{~mm}$ total length, $45 \mathrm{~mm}$ body length, and $118^{\circ}$ point angle, made of high-speed steel (HSS)). Spindle speed was $2800 \mathrm{rpm}$. Drilling feed $42 \mathrm{~m} / \mathrm{min}$ and feed per revolution $0.15 \mathrm{~mm} / \mathrm{rev}$. were applied.

Ninety holes of $10 \mathrm{~mm}$ in depth were made. Thirty of them were made in the birch veneer layer (in the centre of the board, on the mark made in "(A) birch veneer"), in the layer of the adhesive joint (below the centre, the "(B) glue") mark, and in the alder veneer layer (below the joint, marked "(C) alder veneer"). Making holes in particular layers of plywood means that the nominal hole axis is located directly in this layer. The holes in "(A) birch veneer" layer were located perpendicular to the longitudinal section (tangent or radial) of the wood. The holes made in the "(C) alder veneer" layer (in the centre of the 
panel, i.e. above the adhesive joint), were made in the direction perpendicular to the crosssection of the wood. Figure 3 presents holes made in three layers of the plywood board.

(A) Birch veneer

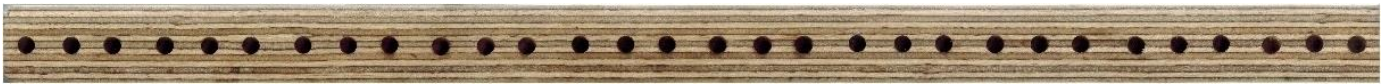

(B) Glue

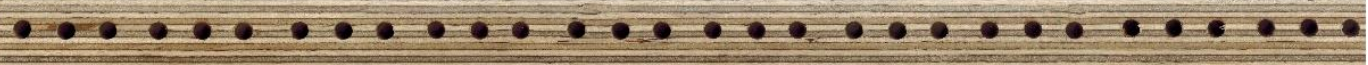

(C) Alder veneer

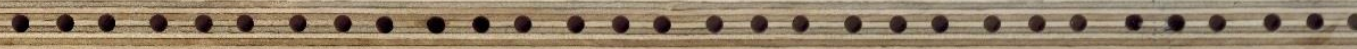

Fig. 3. Holes made in three layers of the plywood

After the holes were made, deviations of their resultant position were measured (the centre distance of each hole from the nominal line on which the centres of all holes should be located). Exemplary deviations of the hole centre position from the nominal line are shown in Fig. 4.

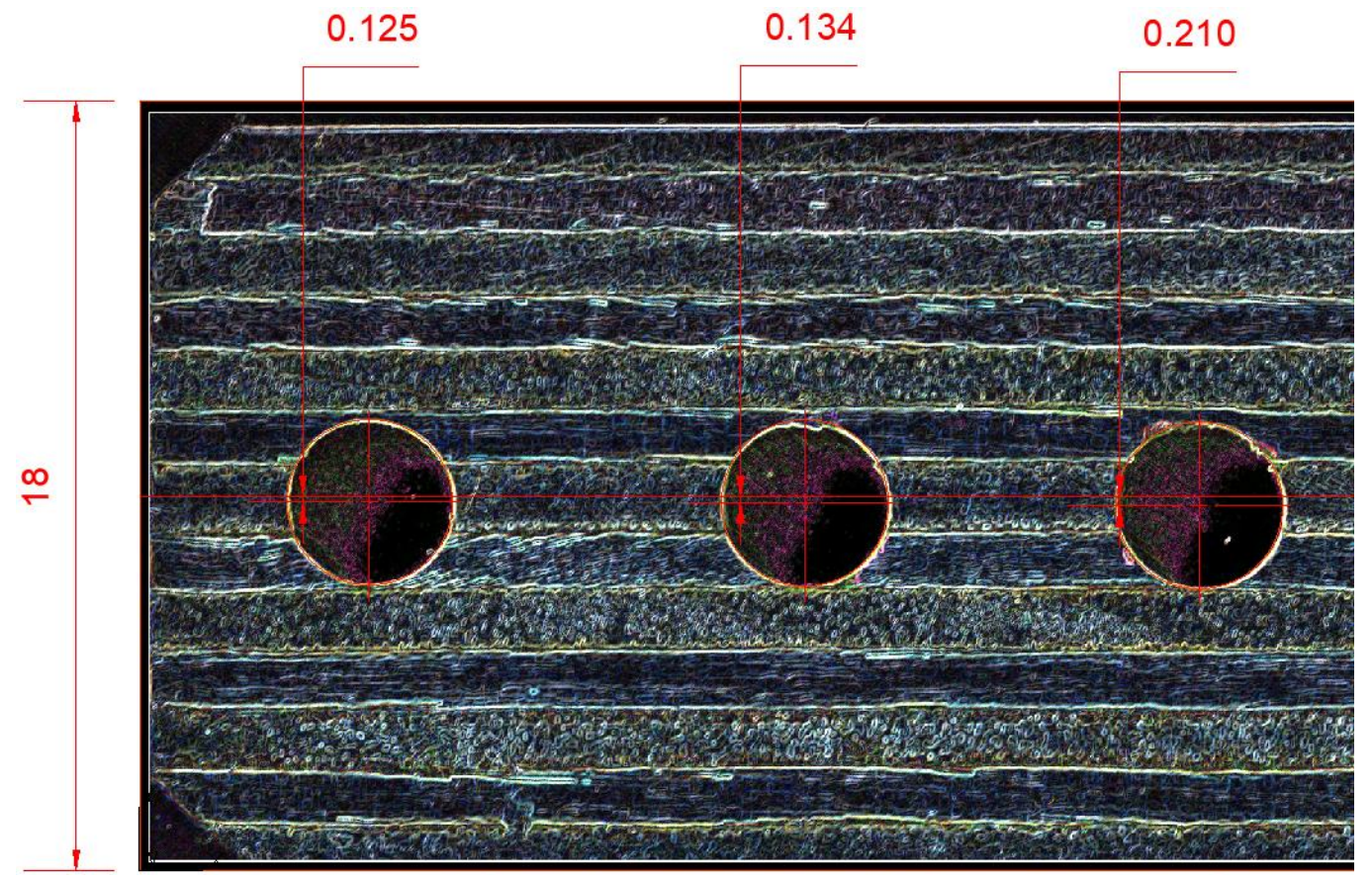

Fig. 4. Exemplary deviations of the hole centre position from the nominal line ("(C) alder veneer")

The inaccuracy of each the hole axis with respect to its nominal axis was measured in a single plane. The measuring directions and an exemplary deviation of the hole axis from the nominal axis are shown in Fig. 5. 

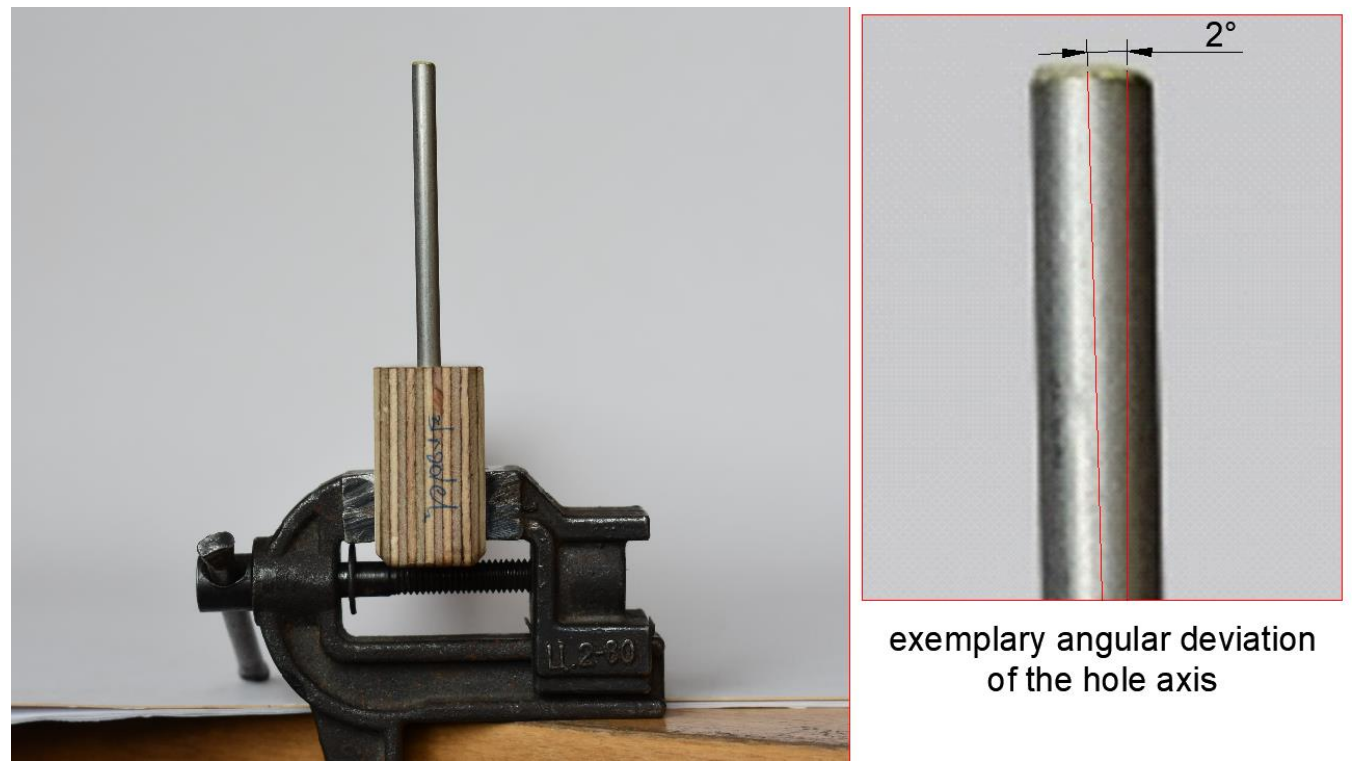

Fig. 5. Direction of angle measurement and exemplary angular inaccuracy of the hole axis (photos by M.S.)

Taking into account the specifics of the tested systems (a hole with a nominal diameter of $3.8 \mathrm{~mm}$ and a depth of $10 \mathrm{~mm}$, drilled in a relatively soft material), non-contact measurements were made, so that measurements did not affect the results (especially in case of the angle deviation of holes axes). For this purpose, a measurement methodology was developed in which the values of the position deviations and angle deviations, and the devi-gradometric applications were employed. To make the photos intended for measurements of the hole position, a 2D scanner was used, and a camera was used to take the angle measurement pictures. The obtained photos were analysed with graphics processing software. The methodology for determining the hole position and the angle deviations can be summarized in following steps:

- Scanning the hole images to TIFF format was made using an image scanner (2D) with a fixed focal length and shallow sharpness;

- Editing was made with Adobe Photoshop CS6 (cropping, improving levels, to obtain a larger tonal range, converting curves to get more details, converting the image to monochrome one);

- Editing with Adobe Illustrator CS6: (import psd file into A3 workspace, gray scale routing, FULL SHADE palette and 25 colour, drawing the line and aligning it in the centre of the routed object, ungrouping of the created solids, selecting hole solids, copying and pasting on new layer, grouping holes (one group consisting of several openings) per each hole, inserting a line under each hole, automatic alignment of the inserted lines with the hole centres, export of the centreline and hole lines to the dxf format file);

- Editing with DraftSight: (all distances from the nominal (centre) line were measured and the obtained data was entered into the spreadsheet table);

- Fixing the sample in a vise, inserting a pin connector to the measured hole, taking a picture with a camera mounted on a tripod. Removing the connector. Repetition of operations for each of 30 holes ( 3 samples were photographed, 30 holes each); 
- Editing photos in Adobe Photoshop CS6 (cropping, image conversion to monochrome, edge detection with Sobel filter);

- Image import to Autodesk Inventory, measurement of angles of the axis deviations of the pin connectors, as compared to the nominal axis; the obtained data was entered into the spreadsheet table.

\section{RESULTS AND ANALYSIS}

\section{Results}

The hole position deviation measurement results (the distance of their centres from the nominal line) are shown in three successive diagrams (Figs. 6 to 8).

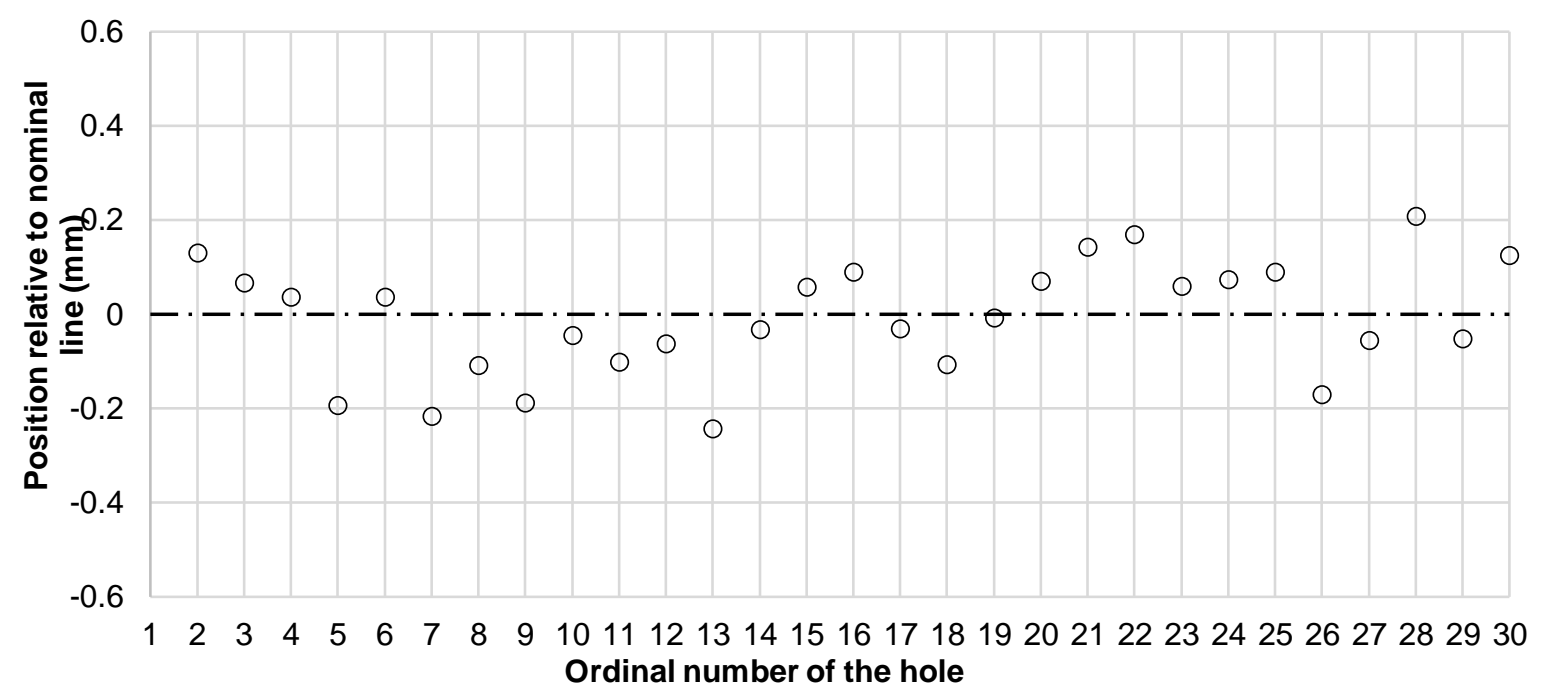

Fig. 6. Hole positions relative to the nominal line in the "(A) birch veneer" layer

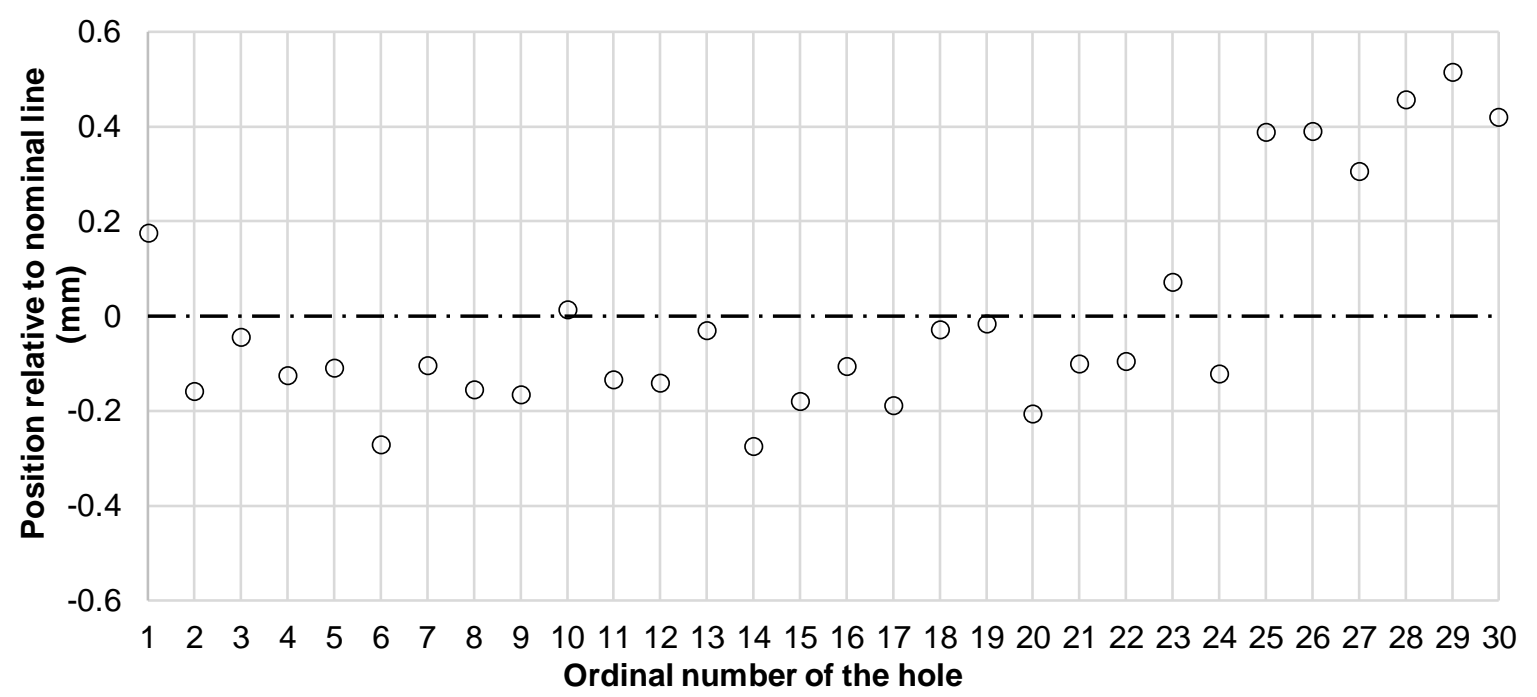

Fig. 7. Hole positions relative to the nominal line in the "(B) glue" layer 


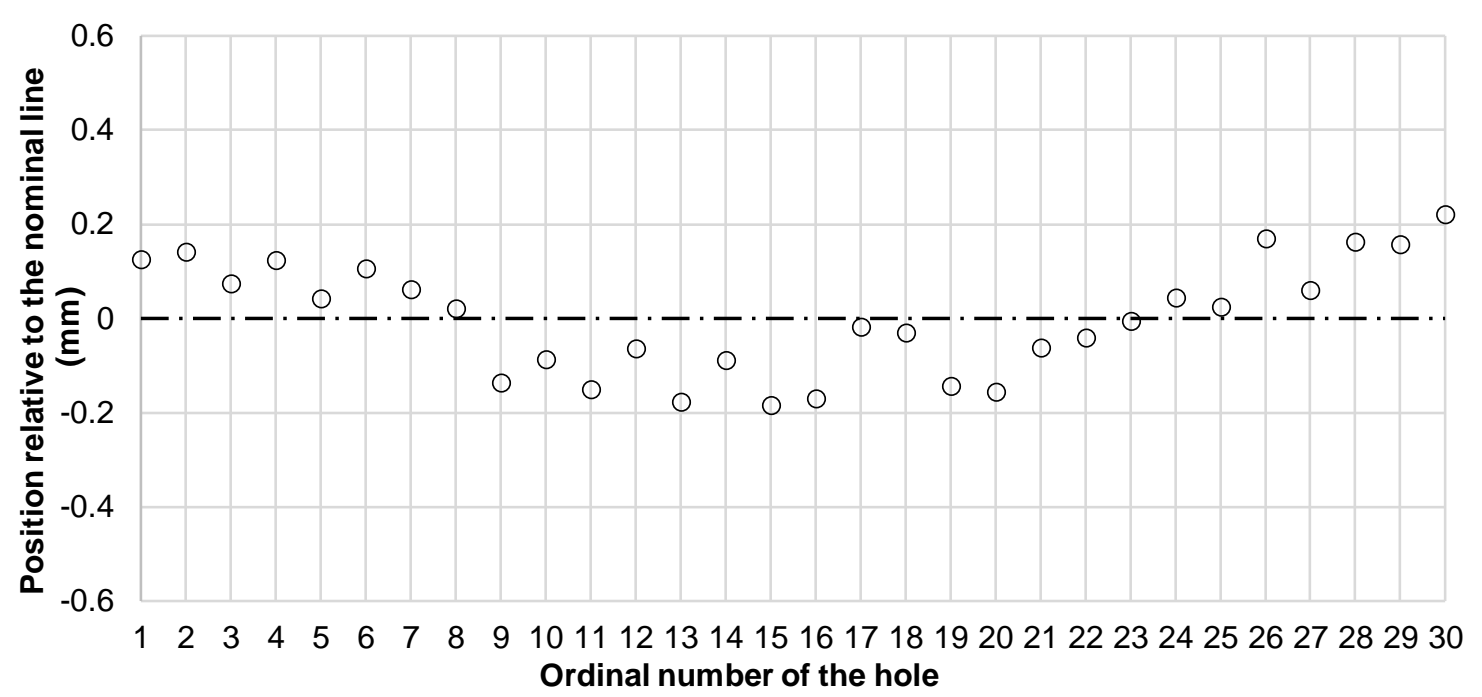

Fig. 8. Hole positions relative to the nominal line in the "(C) alder veneer" layer

The results of the holes axes inaccuracy measurements (deviations of the resultant hole axis from the nominal axis) are shown in three successive diagrams (Figs. 9 to 11).

The presented diagrams (Figs. 6 to 8 ) show non-collinear hole positions. The position of the resultant hole axis relative to the nominal line (machining base) was changed despite the initial, fixed setting of the drill spindles. The angular deviations (Figs. 9 to 11), similar to the holes positions, show displacements in hole axis comparing with initial drill positions. In the case of drilling in the "(A) birch veneer" layer, the deviations assumed positive values in relation to the nominal plane of the drill setting. However, it is difficult to interpret the findings only on the basis of observations. Due to this variability, it was decided to subject the obtained results to a statistical analysis in order to determine the existence of possible dependencies within the scope of the examined machining error parameters.

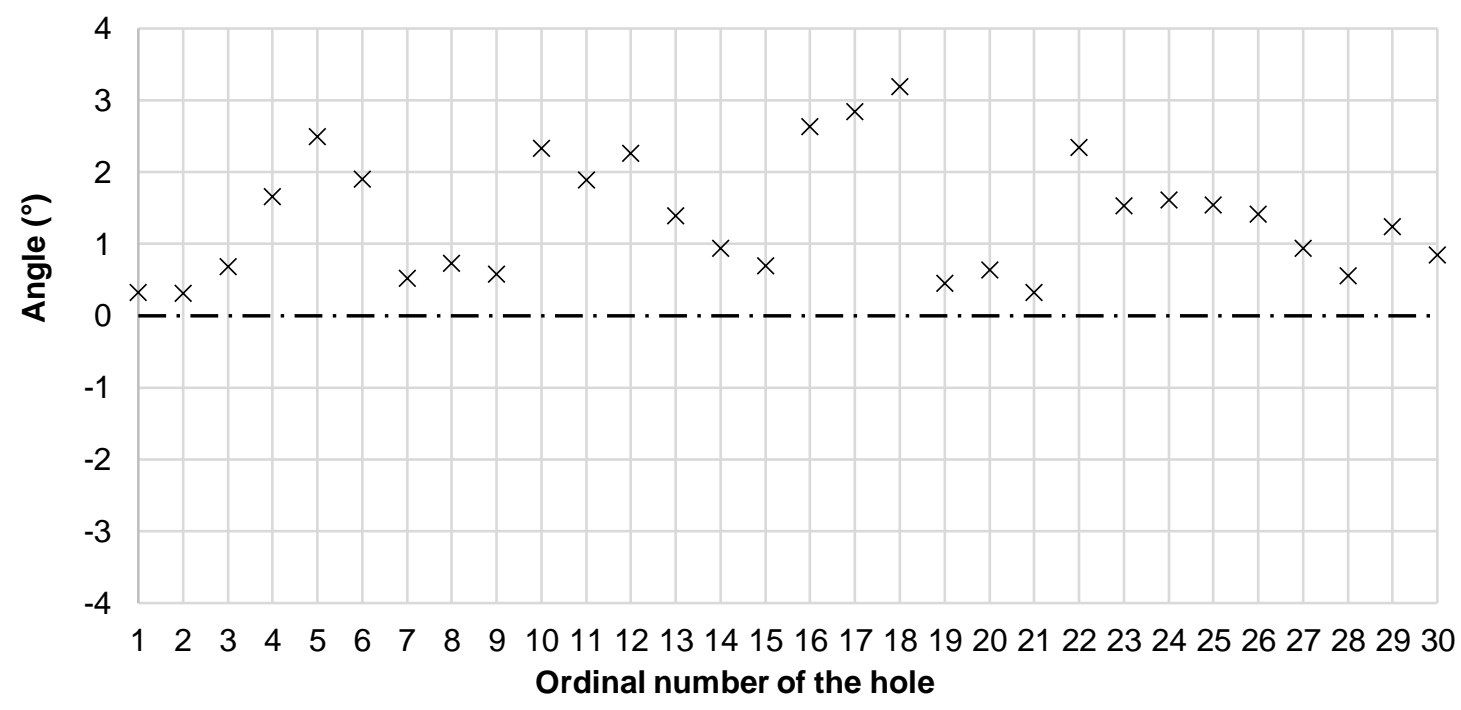

Fig. 9. Hole angles in the "(A) birch veneer" layer 


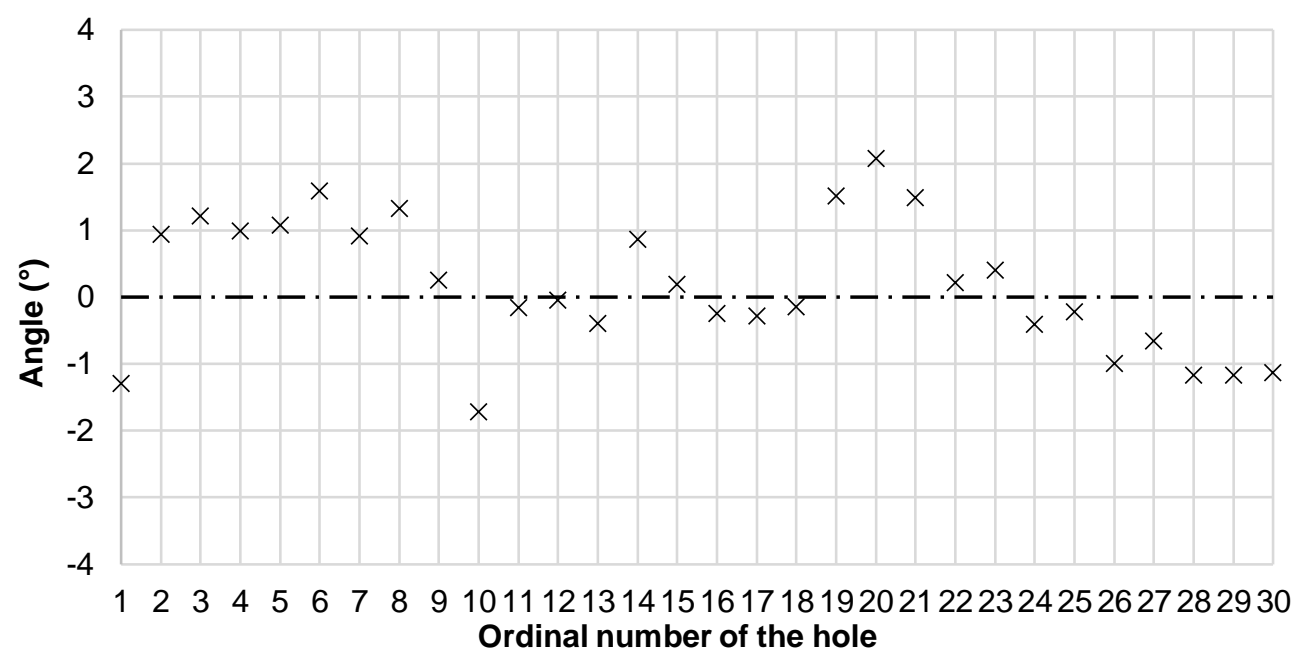

Fig. 10. Hole angles in the "(B) glue" layer

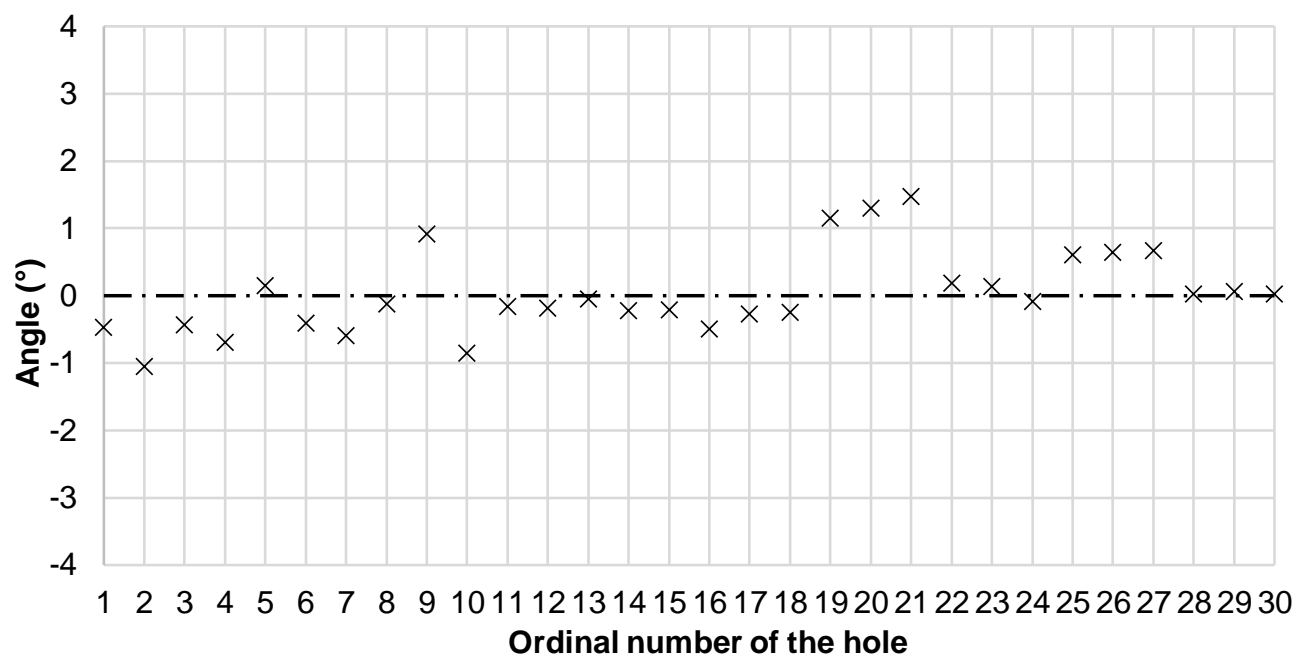

Fig. 11. Hole angles in the "(C) alder veneer" layer

\section{Statistical Analysis of Results}

The basic statistical parameters for the hole position measurements in the three layers of plywood were determined and summarized in Table 3.

Table 3. Main Statistical Parameters of Deviations: Hole Centre Displacement Comparing with Nominal Line and the Angular Deviation from the Nominal Axis

\begin{tabular}{|l|l|c|c|c|c|c|c|c|}
\hline \multicolumn{1}{|c|}{ Layer } & \multicolumn{1}{|c|}{ Property } & Min. & Max. & Aver. & Median & Slant & Kurtos. & SD \\
\hline $\begin{array}{l}\text { (A) } \\
\text { birch } \\
\text { veneer" }\end{array}$ & $\begin{array}{l}\text { Position displacement } \\
(\mathrm{mm})\end{array}$ & -0.242 & 0.209 & 0.102 & 0.090 & -0.263 & -0.799 & 0.065 \\
\cline { 2 - 9 } & Angular displacement $\left(^{\circ}\right)$ & 0.312 & 3.180 & 1.374 & 1.384 & 0.480 & -0.902 & 0.855 \\
\hline $\begin{array}{l}\text { "(B) } \\
\text { glue" }\end{array}$ & $\begin{array}{l}\text { Position displacement } \\
(\mathrm{mm})\end{array}$ & -0.275 & 0.516 & 0.183 & 0.147 & 1.121 & -0.036 & 0.134 \\
\cline { 2 - 9 } & Angular displacement $\left(^{\circ}\right)$ & -1.726 & 2.075 & 0.837 & 0.921 & 0.007 & -0.929 & 0.550 \\
\hline \multirow{2}{*}{$\begin{array}{l}\text { "(C) } \\
\text { alder } \\
\text { veneer" }\end{array}$} & $\begin{array}{l}\text { Position displacement } \\
(\mathrm{mm})\end{array}$ & -0.185 & 0.170 & 0.097 & 0.090 & -0.042 & -1.250 & 0.058 \\
\cline { 2 - 9 } & Angular displacement $\left(^{\circ}\right)$ & -1.055 & 1.476 & 0.477 & 0.400 & 0.735 & 0.094 & 0.398 \\
\hline
\end{tabular}


With regard to the hole position, the mean value and the median deviations showed the highest drilling variant values for holes drilled in the adhesive layer. The average deviation in the hole position for ("(B) glue") adhesive was almost twice as high as for both ("(A) birch veneer "And" (C) alder veneer ") veneers. Similarly, the standard deviation was more than twice as high in this case. Also, the median deviation of the hole position was much larger for adhesive layer than for veneer layers, where the values were the same. In addition, the adhesive layer holes median was the most different from the average deviation of the hole position. This indicates a large discrepancy in the individual measurement results.

The kurtosis of deviation position distribution was negative everywhere, which indicates that the results close to the average were minor while the extreme ones were more frequent. Negative kurtosis absolute value was inversely proportional to the standard deviation. The distribution of hole position skewness, for birch and alder veneer layers, was negative (left-inclined distribution) while positive for the right-inclined distribution.

No statistical relationships were found for deviations of the hole axis angle. This indicates that these errors were essentially accidental and not related to the place of drilling and position deviations. In order to determine possible correlations between the values of deviations in the position of holes drilled in particular layers, linear functions were determined for their corrected position. Next, the upper and lower limits of these functions were calculated based on definitions ('Upper and lower limits', 1993): $\liminf _{n \rightarrow \infty} a_{n} \stackrel{\text { def }}{=}$ $\lim _{n \rightarrow \infty}\left(\inf _{k \geq n} a_{k}\right)=\sup _{n \geq 0} \inf _{k \geq n} a_{k}$ and $\limsup _{n \rightarrow \infty} a_{n} \stackrel{\text { def }}{=} \lim _{n \rightarrow \infty}\left(\sup _{k \geq n} a_{k}\right)=\inf _{n \geq 0} \sup _{k \geq n} a_{k}$. The linear function of the position deviation for hole drilled in the "(A) birch veneer" layer, takes the form of: $y=$ $0.0007 x+0.0953$. The lower limit of the function at the point for the minimum value is: $\liminf _{x \rightarrow 0,00695} f(x)=0.0953$, while the upper is $\limsup _{x \rightarrow 0.24235} f(x)=0.09546$. For the position of the holes drilled in the "(B) glue" layer, the linear function formula was determined: $y=$ $0.0085 x+0.0517$. The lower limit in the point for the minimum value of this function is: $\liminf _{x \rightarrow 0.01415} f(x)=0.05182$, while the upper is - $\limsup _{x \rightarrow 0.51625} f(x)=0.05608$. For the absolute value of the drilled holes in the "(C) alder veneer" layer, the function and its limits were also determined. The linear function formula was found to be: $y=0.0006 x+0.0921$. The lower limit at the point for the minimum value of this function is: $\liminf _{x \rightarrow 0.0063} f(x)=$ 0.09210 , while the upper is $\limsup _{x \rightarrow 0.2203} f(x)=0.09223$. The determined upper and lower

limit values indicate the range of maximum deviations from the base position the values of the hole positions fall into. On the basis of obtained deviation results for both hole positions and displacement angle, a correlation analysis was performed. The correlation matrix for the hole positions of A, B and C layers was determined (Table 4) and for the hole angle in the $\mathrm{A}, \mathrm{B}$, and $\mathrm{C}$ layers (Table 5).

Table 4. Correlation of the Position of Holes Drilled in Individual Plywood Layers

\begin{tabular}{llll}
\hline & “(A) birch veneer” “(B) glue” “(C) alder veneer” & & \\
\hline “(A) birch veneer” & 1 & & \\
“(B) glue” & 0.343057 & 1 & \\
“(C) alder veneer” & -0.0689 & 0.322958 & 1 \\
\hline
\end{tabular}


Table 5. Correlations of Deviations of the Axis Angle, Holes Drilled in Individual Layers of Plywood

\begin{tabular}{lccc}
\hline & “(A) birch veneer” “(B) glue” “(C) alder veneer” \\
\hline "(A) birch veneer” & 1 & & \\
“(B) glue” & -0.44537 & 1 & \\
“(C) alder veneer” & -0.38097 & 0.457768 & 1 \\
\hline
\end{tabular}

Next, correlations between the deviations of the hole position and the hole angle were determined, which were respectively for the following layers: A -0.16306 , B: 0.120616 and C: 0.081483 . There were no statistically significant relationships between the values of the hole axis deviations and the angular deviations of the hole axis.

\section{CONCLUSIONS}

The obtained results confirm the hypothesis that the adhesive layer negatively affected the accuracy of the position and the angle of the holes in the case of drilling deep holes in the side of the plywood board. The experiment described in this article has been limited to one value of feed and one type of plywood. Future research could concern the influence of different feed values on inaccuracies of drilled holes in veneer layers and adhesive layers. They may also concern the inter-material properties of different plywood on the obtained dimensional accuracy of holes.

1. The spread of hole positions for the adhesive layer ("(B) glue") was about twice as large as for the other layers. In the case of the "(B) glue", the standard deviation of the hole position was $0.134 \mathrm{~mm}$, while in the "(A) birch veneer" layer it was $-0.065 \mathrm{~mm}$, and $0.058 \mathrm{~mm}$ in the "(C) alder veneer" layer. So, there was a much greater tendency to drill wandering when drilling in this layer. This indicates a clear impact of the difference in adhesive ("(B) glue") properties and the adjacent veneer layers properties of ("(A) birch veneer" and "(C) alder veneer") layers. It can be deduced that large differences in properties increase the drill slipping tendency (during the second drilling phase). This slippage occurs in the direction of wooden veneers and, as a result, causes the centres of holes drilled in the gluing joint to have a greater deviation from the nominal position (machining base).

2. In all the individual three layers ("(A) birch veneer", "(B) glue" and "(C) alder veneer"), no correlation was found between the forms of hole position distribution.

3. There was no correlation between position deviations and angle deviations for any of the three layers; (position vs angle for "(A) birch veneer", position vs angle for "(B) glue" and position vs angle for "(C) alder veneer") layers. This indicates a lack of relationship between the phenomena occurring in the second phase of drilling (affecting the hole position) and the phenomena occurring during the third drilling phase (affecting the deviation of the hole angle from the nominal axis).

4. There were no statistically significant differences in angular deviations for individual layers. Standard deviations developed as follows: "(A) birch veneer" $-0.855^{\circ}$, “(B) 
glue" $-0.550^{\circ}$, " $(\mathrm{C})$ alder veneer" $-0.398^{\circ}$. The obtained results indicate that the deviations in the hole axis from the nominal values are stochastic, and the differences in the layer properties do not significantly affect the directions and values of the angular deflection.

5. General technological recommendations resulting from the experiment: no drill diameter smaller than $3.8 \mathrm{~mm}$ can be used and the feed per revolution in the second drilling phase should be reduced to less than $0.15 \mathrm{~mm} / \mathrm{rev}$. in order to maintain hole accuracy.

\section{AUTHOR CONTRIBUTIONS}

The following co-authors were responsible for: conceptualization, M.S.; methodology, M.S.; software, M.S.; validation, M.S. and; formal analysis, K.S-S.; investigation, M.S.; resources, M.S.; data curation, M.S.; writing original draft preparation, M.S.; writing review and editing, M.S. and T.R.; visualization, M.S.; supervision, M.S.; project administration, K.S.; funding acquisition, K.S.

\section{ACKNOWLEDGMENTS}

1. This research was funded by The National Centre for Research and Development (Narodowe Centrum Badań i Rozwoju), grant number POIR.01.01.01-00-0746/17 "LOCOSYSTEM - Polymorphic furniture system". The APC was funded by The National Centre for Research and Development (Narodowe Centrum Badań i Rozwoju).

2. The authors thank mgr inż. Mateusz Ligocki for technical support in the analysis of measurement results.

\section{REFERENCES CITED}

Branowski, B., Zabłocki, M., and Sydor, M. (2018). "Experimental analysis of new furniture joints," BioResources 13(1), 370-382. DOI: 10.15376/biores.13.1.370-382

Gong, Y., Lin, C., and Ehmann, K. F. (2005). "Dynamics of initial penetration in drilling: Part 1-Mechanistic model for dynamic forces," Journal of Manufacturing Science and Engineering 127(2), 280-288. DOI: 10.1115/1.1852569

Goodell, H., and Phillips, R. (1944). Effects of Different Methods of Drilling Bolt Holes in Wood and Plywood (No. 1523; p. 22). Retrieved from United States Department of Agriculture Forest Service Forest Products Laboratory website: https://ir.library.oregonstate.edu/downloads/m326m565t

Guo, X., Zhu, Z., Ekevad, M., Bao, X., and Cao, P. (2018). "The cutting performance of $\mathrm{Al}_{2} \mathrm{O}_{3}$ and $\mathrm{Si}_{3} \mathrm{~N}_{4}$ ceramic cutting tools in the milling plywood," Advances in Applied Ceramics 117(1), 16-22. DOI: 10.1080/17436753.2017.1368946

Kudryavtsev, L. D. (1993). "Upper and lower limits," in: Encyclopaedia of Mathematics, M. Hazewinkel (ed.), Kluwer, Berlin, Vol. 9. 
Laskowska, K., and Sydor, M. (2018). "Polymorphic furniture system in furniture users' expectations," Annals of WULS - SGGW. Forestry and Wood Technology 104, 446453.

Podziewski, P., and Górski, J. (2011). "Relationship between machining conditions and feed force during drilling in some wood-based materials," Annals of Warsaw University of Life Sciences-SGGW, Forestry and Wood Technology 75, 216-219.

Podziewski, P., and Górski, J. (2012). "Effect of the feed rate on the cutting forces during drilling in a standard hardwood plywood," Annals of WULS-SGGW. Forestry and Wood Technology 79, 170-172.

Podziewski, P., Szymanowski, K., Górski, J., and Czarniak, P. (2018). "Relative machinability of wood-based boards in the case of drilling-Experimental study," BioResources 13(1), 1761-1772. DOI: 10.15376/biores.13.1.1761-1772

Rogoziński, T., Wilkowski, J., Górski, J., Czarniak, P., Podziewski, P., and Szymanowski, K. (2015). "Dust creation in CNC drilling of wood composites," BioResources 10(2), 3657-3665. DOI: 10.15376/biores.10.2.3657-3665

Smardzewski, J. (2015). "Furniture design," Retrieved from https://doi.org/10.1007/9783-319-19533-9

Starczewski, K. (2016). “Shelving Unit, ” UPRP Patent No. PL 223915 B1. Retrieved from lens.org/lens/patent/043-615-454-546-093

Sydor, M. (2019). "Geometry of wood screws: A patent review," European Journal of Wood and Wood Products 77(1), 93-103. DOI: 10.1007/s00107-018-1362-4

Sydor, M., and Wieloch, G. (2009). "Construction properties of wood taken into consideration in engineering practice," Drewno. Prace Naukowe. Doniesienia. Komunikaty 52(181), 63-73.

Article submitted: August 5, 2019; Peer review completed: October 19, 2019; Revised version received: October 30, 2019; Accepted: November 5, 2019; Published: November $8,2019$.

DOI: 10.15376/biores.15.1.117-129 